\title{
Endurantism Endures: Rejoinder to Barker and Dowe
}

\section{Brian Garret}

Australian National University

College of Arts and Social Sciences

Department of Philosophy

Canberra Australian Capital Territory

Australia

brian.garrett@anu.edu.au

Article info

CDD: 121

Received: 06.07.2017; Revised: 27.09.2017; Accepted: 04.10.2017

DOI: http://dx.doi.org/10.1590/0100-6045.2017.V40N3.BG

Keywords:

Enduratism

Perdurantism

\section{ABSTRACT}

In Barker and Dowe (2005), Stephen Barker and Phil Dowe present a range of arguments which they take to demonstrate the paradoxical nature of endurantism. I claim that the endurantist has convincing replies to each argument.

In Barker and Dowe (2005), Stephen Barker and Phil Dowe offer a range of arguments intended to show that endurance is paradoxical. I argue that all fail.

(i) Since some stage-setting is required, I quote the first argument in full (Barker and Dowe cite Beebee and Rush (2003) for this description):

Eric is a (short-lived) cat. He persists for $100 n$, for some small temporal unit $n$, and thus, assuming Endurantism, is multi-located throughout a 4-D spacetime region $\mathrm{R}$ of $100 n$ temporal size. Consider the 100 temporal slices $r 1, r 2$, $\ldots, r 100$ of the region $\mathrm{R}$, where each $r$ has temporal length $n$. At each region $r$, there is an object, a cat: Eric at $r$. We refer collectively to these objects as the Ericrs. Take the fusion, or mereological sum, of the Eric $r$ s and call this fusion $\mathrm{F}($ Eric $r$ ). Our first paradox of multilocation (version 2) goes as follows: 
(a) F(Ericr) is the fusion of the Ericrs, which are all identical to Eric since Eric at any $r$ is just Eric. So F(Ericr) is identical to each Ericr. As each Ericr has temporal extent n, F(Ericr) has temporal extent n. But (b) $\mathrm{F}$ (Ericr) has a part at each $\mathrm{r}$ of R. So F(Ericr) is an object with temporal extent 100n. Thus F(Ericr)'s temporal extent both is and is not greater than n. Paradox. (Barker and Dowe: 69-70)

How should an endurantist respond? The endurantist has to deny the second sentence in (a), vir., that $\mathrm{F}$ (Ericr) is identical to each Eric $r$ (i.e., to Eric). For $\mathrm{F}$ (Ericr) is a four-dimensional object and Eric is not. (See Beebee and Rush (2003): 313 for a similar response.) Hence, the endurantist must either reject the first sentence in (a) or deny that it implies the second. The first sentence is true only if the occurrence there of 'all' is understood as 'each'. F(Eric $r$ ) is the fusion of the Ericrs, each of which is Eric. But it does not follow from this that the fusion is Eric. A fusion of trees is not a tree; and a fusion of 'Erics' is not a cat (hence not Eric). Instead, F(Ericr) is a fusion of 100 distinct states of affairs involving Eric (since Eric will have different properties at each of these 100 times). Hence, the endurantist will regard $\mathrm{F}$ (Ericr) as a four-dimensional entity corresponding to Eric's life-history, but not identical to Eric.

Moreover, and this I take to be a new point, it can be demonstrated that $\mathrm{F}($ Eric $r) \neq$ Eric. Consider some sub-region of $\mathrm{R}, \mathrm{R}^{*}$, of $50 \mathrm{n}$ temporal size. Call the fusion of Eric $r^{*}$ s, F(Eric $\left.r^{*}\right)$. By Barker and Dowe's (a)-style reasoning, Eric $=\mathrm{F}\left(\right.$ Eric $\left.r^{*}\right)$. If Eric $=\mathrm{F}($ Eric $r)$ and Eric $=\mathrm{F}\left(\right.$ Eric $\left.r^{*}\right), \mathrm{F}($ Eric $r)=\mathrm{F}\left(\right.$ Eric $\left.r^{*}\right)$. But this must be wrong since these fusions occupy different spatio-temporal regions. Hence, Eric cannot be identical to any fusion.

\section{(ii) Barker and Dowe then present an argument using plural reference rather than mereology:}

The Ericrs occupy $R$ (they fill up $R$ ).

Eric does not occupy $R$ (by Endurantism - he is multi-located throughout $R$ ).

The Ericrs are one and the same; they are Eric (by Endurantism). Therefore, the Ericrs occupy and don't occupy R. (Barker and Dowe: 70). 
This argument has not been addressed in the literature, but it fares no better than the previous one. The endurantist will insist that the first premise is true only if understood as the claim that Eric persists through $R$, i.e., that he exists at each region $\mathrm{r} 1$ through $\mathrm{r} 100$ and so is multi-located throughout $R$. Understood thus, all three premises are consistent with each other and so the argument collapses.

(iii) Barker and Dowe next offer the following argument:
We accept that there are lives, which are 4-D entities, with beginnings, middles and ends. Call the life of Eric, L(Eric). There is a necessary connection between lives and the things that have them. So by the Humean principle that there are no necessary connections between distinct existences it must be that Eric and L(Eric) overlap. We think this means that one must accept that Eric is part of $\mathrm{L}$ (Eric). Now the paradox goes as follows according to BR (315). Divide L(Eric) into two non-overlapping temporal stage: $\mathrm{L}$ (Eric) 1 and $\mathrm{L}$ (Eric) 2 . $\mathrm{L}$ (Eric) 1 is located at R1, and nowhere else, and L(Eric) 2 is located at R2, and nowhere else. By hypothesis, Eric is part of $\mathrm{L}$ (Eric). So Eric is part of $\mathrm{L}$ (Eric)1. But Eric is located at rs that are not in R1, so L(Eric)1 cannot, contrary to hypothesis, be confined to R1, since Eric is part of L(Eric)1. Similarly for L(Eric)2. Paradox. (Barker and Dowe: 73).

How should the endurantist respond? Barker and Dowe claim that there is a '... necessary connection between lives and the things that have them.' (Barker and Dowe: 73). But this claim is vague. Presumably they are not denying that Eric's life could have gone differently than it actually did. Do they just mean, what everyone accepts, that the life of Eric is necessarily the life of Eric? In addition, the Humean principle they cite is now regarded as far from obvious, in light of plausible Kripkean theses such as the necessity of origin.

However, even if we waive these worries, why should the endurantist accept that Eric is part of L(Eric)? 'L(Eric)' presumably means 'the events that comprise Eric's life'. The parts of L(Eric) are therefore events. Since the endurantist denies that Eric is an event, he will deny that Eric is part of $\mathrm{L}$ (Eric). The totality of things that happen to Eric constitute his life; hence the things that happen to Eric are parts of his life. But, the endurantist insists, Eric is not part of his life. 
In sum, Barker and Dowe's arguments against endurantism can be resisted.

\section{References}

BARKER, S and Dowe, P. Paradoxes of multi-location. Analysis 63.2: 106-114, 2003. and __ Endurance is paradoxical. Analysis 65.1: 69-74, 2005.

BEEBEE, $\mathrm{H}$ and Rush, M. Non-paradoxical multi-location.

Analysis 63.4: 311-17, 2003.

MCDANIEL, K. No paradox of multi-location. Analysis 63.4: 309-311, 2003. 